\title{
Article \\ A Trial Acoustic Improvement in a Lecture Hall with MPP Sound Absorbers and FDTD Acoustic Simulations
}

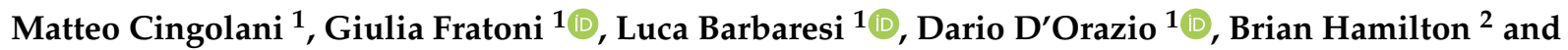 \\ Massimo Garai ${ }^{1, *(1)}$
}

1 Department of Industrial Engineering, University of Bologna, 40136 Bologna, Italy; matteo.cingolani6@unibo.it (M.C.); giulia.fratoni2@unibo.it (G.F.); luca.barbaresi@unibo.it (L.B.); dario.dorazio@unibo.it (D.D.)

2 Acoustics and Audio Group, University of Edinburgh, Edinburgh EH8 9DF, UK; brian.hamilton@ed.ac.uk

* Correspondence: massimo.garai@unibo.it

\section{check for} updates

Citation: Cingolani, M.; Fratoni, G.; Barbaresi, L.; D'Orazio, D.; Hamilton,

B.; Garai, M. A Trial Acoustic Improvement in a Lecture Hall with MPP Sound Absorbers and FDTD Acoustic Simulations. Appl. Sci. 2021, 11, 2445. https://doi.org/10.3390/ app11062445

Academic Editors: Nikolaos M. Papadakis, Massimo Garai and Stavroulakis Georgios

Received: 23 January 2021

Accepted: 3 March 2021

Published: 10 March 2021

Publisher's Note: MDPI stays neutral with regard to jurisdictional claims in published maps and institutional affiliations.

Copyright: (c) 2021 by the authors. Licensee MDPI, Basel, Switzerland. This article is an open access article distributed under the terms and conditions of the Creative Commons Attribution (CC BY) license (https:/ / creativecommons.org/licenses/by/ $4.0 /)$.

\begin{abstract}
Sound absorbing micro-perforated panels (MPPs) are being increasingly used because of their high quality in terms of hygiene, sustainability and durability. The present work investigates the feasibility and the performance of MPPs when used as an acoustic treatment in lecture rooms. With this purpose, three different micro-perforated steel specimens were first designed following existing predictive models and then physically manufactured through 3D additive metal printing. The specimens' acoustic behavior was analyzed with experimental measurements in single-layer and double-layer configurations. Then, the investigation was focused on the application of double-layer MPPs to the ceiling of an existing university lecture hall to enhance speech intelligibility. Numerical simulations were carried out using a full-spectrum wave-based method: a finite-difference time-domain (FDTD) code was chosen to better handle time-dependent signals as the verbal communication. The present work proposes a workflow to explore the suitability of a specific material to speech requirements. The measured specific impedance complex values allowed to derive the input data referred to MPPs in FDTD simulations. The outcomes of the process show the influence of the acoustic treatment in terms of reverberation time $\left(\mathrm{T}_{30}\right)$ and sound clarity $\left(\mathrm{C}_{50}\right)$. A systematic comparison with a standard geometrical acoustic (GA) technique is reported as well.
\end{abstract}

Keywords: acoustics; micro-perforated panels; FDTD simulation; speech intelligibility

\section{Introduction}

Nowadays, the interest in sound absorbing materials is growing due to the variety of their possible applications, from room acoustics [1] to environmental noise control [2,3]. Porous and fibrous absorbers [4-6] have until now been the most used materials in noise control application because of their high performance-to-cost ratio in the frequency band of interest. In the last decades, new requirements have become important, such as durability, recyclability, hygienic problems, environmental sustainability and optical transparency, which are no longer suitable for porous and fibrous materials. In order to satisfy these requirements, specific classes of sound absorbing materials have been proposed: among them, micro-perforated panels (MPPs) [7-11]. During the 1970s, the first MPP acoustic model proposed by Maa [7] defined the absorbers as a combination of a thin panel with sub-millimetric holes, an air cavity and a rigid wall. The air cavity is required to perform a Helmholtz-type resonance. Moreover, an equivalent fluid (EF) model was theorized by Atalla and Sgard [12]. In the last decades, the applications, the improvements and the theoretical developments of such materials have been extensively studied and MPP multiple-layers have been introduced to provide wide-band absorption, creating more efficient sound absorbing systems [13-15].

MPPs can be made of various materials, including plywood, glass and sheet metal. Therefore, they are extremely attractive from an ecological point of view, especially for 
architectural applications [16,17]. Among the potential applications of MPPs, there is their use as an acoustic treatment in existing lecture rooms to enhance the verbal communication conditions [18]. Reducing the reverberant field in a specific frequency range contributes to decreasing the vocal effort of the speaker and the distraction of the students [19-21]. Since in the last years the acoustical comfort of teachers and students is one of the most debated topics [22-24], the possibility to choose a sustainable and high-performance material could meet the need of improving the acoustics in existing lecture halls.

In this work, three steel MPP specimens were designed with specific constitutive geometrical parameters. The sound absorption mathematical equations and the electro-acoustic analogies were used to simplify complex mechanical issues into equivalent electrical circuits. The specimens were constructed using $3 \mathrm{D}$ additive printing and the manufacturing issues encountered during the process are described and shown in detail. Experimental measurements made with the transfer-function method [25] in an impedance tube [26] are reported and compared with predictive models. An optimization of MATLAB implementations was carried out taking into account the practical issues encountered during the measurements. After the experimental phase, the performance of MPPs was evaluated focusing on the application to large-scale rooms. In particular, the effects of MPPs as an acoustic treatment in an existing lecture hall previously surveyed [27] were explored by means of full-spectrum finite-difference time-domain (FDTD) simulations [28].

\section{Modeling the Sound Absorption of Micro-Perforated Panels (MPP)}

A micro-perforated panel consists of a thin panel with a specific perforation ratio made by a distribution of sub-millimeter holes backed by an air cavity and a rigid wall, as shown in Figure 1.

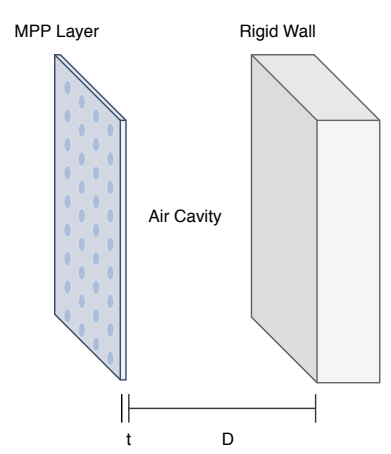

Figure 1. Schematic representation of a single-layer micro-perforated panel (MPP) and its dimensional parameters.

The acoustic complex impedance of an MPP $(Z)$ is the result of different contributions: the real part of the impedance that needs to be matched to the air impedance $\left(Z_{0}\right)$ and the imaginary part of the impedance provided by the air cavity and the perforations. The values of the perforation diameter $d$, the thickness of the panel $t$, the porosity $\phi$ and the air cavity thickness $D$ are the four constitutive parameters that influence the range of frequencies absorbed and the bandwidth as well. Taking into account Maa's definition [8] and according to Cobo's notation [13], it is possible to define the input complex impedance of a single-layer (SL) MPP $Z_{1}$ as follows:

$$
Z_{1, S L}=Z_{\text {holes }}+Z_{\text {edge }}+Z_{c} .
$$

The impedance $Z_{\text {holes }}$ defines the viscous dissipation within the holes, $Z_{\text {edge }}$ the distortion of the flow in the perforation edges and $Z_{c}$ is the resonance in the air cavity:

$$
Z_{\text {holes }}=\frac{\Delta p}{u}=i \frac{\omega \rho_{0}}{\phi}\left[1-\frac{2}{s \sqrt{-i}} \frac{J_{1}(s \sqrt{-i})}{J_{0}(s \sqrt{-1})}\right]^{-1}
$$




$$
Z_{\text {edge }}=R_{s}+i X_{m}=2 \sqrt{2 \eta \omega \rho_{0}}+i \frac{\omega \rho_{0} 0.85 d}{F(\epsilon)}
$$

where $\Delta p$ is the pressure difference at both sides of the tubes, $u$ is the particle velocity in the tube, $\rho_{0}$ is the air density, $\eta$ is the air dynamic viscosity, $\phi$ is the porosity, $s=d \sqrt{\frac{\omega \rho_{0}}{4 \eta}}$ is the perforation constant ( $d$ being the diameter of the holes), $J_{1}$ and $J_{0}$ the Bessel functions of first-class and order 1 and 0 , respectively, and $F(\epsilon)$ is the Fok function, a correction factor of the mass reactance [13] and $\epsilon=\sqrt{\phi}$. Considering all the parameters introduced so far, it is possible to study the equivalent electro-acoustic system for the MPP, as shown in Figure 2.
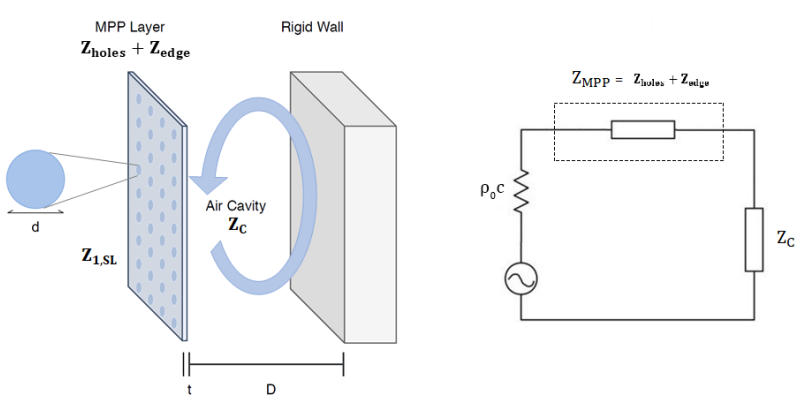

Figure 2. Single-layer (SL)-MPP schematic representation (left) and the corresponding equivalent electrical system (right).

In practice, multiple-layer MPPs are usually preferred because of their extended absorption band.

A double-layer MPP (DL-MPP) consists of two MPPs with impedances $Z_{M P P, 1}$ and $Z_{M P P, 2}$ and two air cavities with impedances $Z_{c 1}$ and $Z_{c 2}$ (see Figure 3). Considering the sound waves passing through the DL-MPP system from left to right at normal incidence, the input impedance to the DL-MPP system is:

$$
Z_{1, D L}=Z_{\text {holes }, 1}+Z_{\text {edge, } 1}+Z_{0} \frac{Z_{2, D L} \cos \left(k D_{2}\right)+i Z_{0} \sin \left(k D_{1}\right)}{Z_{0} \cos \left(k D_{1}\right)+i Z_{2, D L} \sin \left(k D_{2}\right)}
$$

with

$$
Z_{2, D L}=Z_{\text {edge, } 2}+Z_{\text {holes }, 2}+Z_{c 2} \text {. }
$$

Therefore, the absorption of a DL-MPP globally depends on eight constitutive and geometrical parameters, four for the first layer and four for the second layer: the diameter of the holes $\left(d_{1}, d_{2}\right)$, the thickness $\left(t_{1}, t_{2}\right)$, the distance $\left(D_{1}, D_{2}\right)$, and the porosity $\left(\phi_{1}, \phi_{2}\right)$. For this reason, it is difficult to predict the acoustic performance of a DL-MPP and to find, a priori, a combination of these parameters providing the maximum absorption in a specific frequency range.
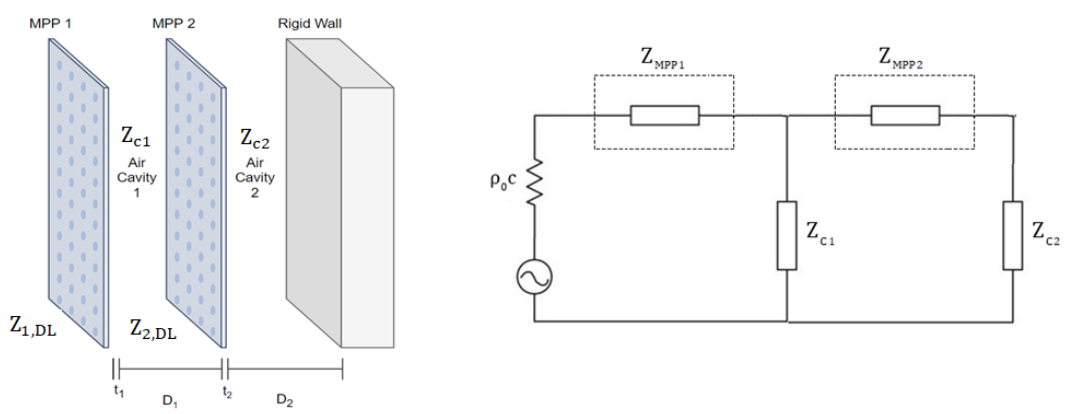

Figure 3. Double-layer (DL)-MPP schematic representation (left) and the corresponding equivalent electrical system (right). 
Atalla and Sgard [12] introduced the so-called equivalent fluid (EF) model following the Johnson-Champoux-Allard approach with an equivalent tortuosity [5]: they assumed an MPP coupled at both sides to a semi-infinite fluid. All of the phenomena involved are recalled in Figure 4. In the EF model, the viscous boundary within the perforations and around the edges is represented by the resistive part of the normal surface impedance, and the movement of the air cylinder-the length of which is greater than the panel thicknessis taken into account in the reactive part of the MPP impedance. In addition to this, a new length correction is introduced in order to consider the increase of air mass vibrating inside the cylinder. Allard demonstrated that the viscous and thermal lengths $\left(\Lambda\right.$ and $\Lambda^{\prime}$, respectively) can be considered equal to the hydraulic radius of the perforations in case of straight cylindrical pores.
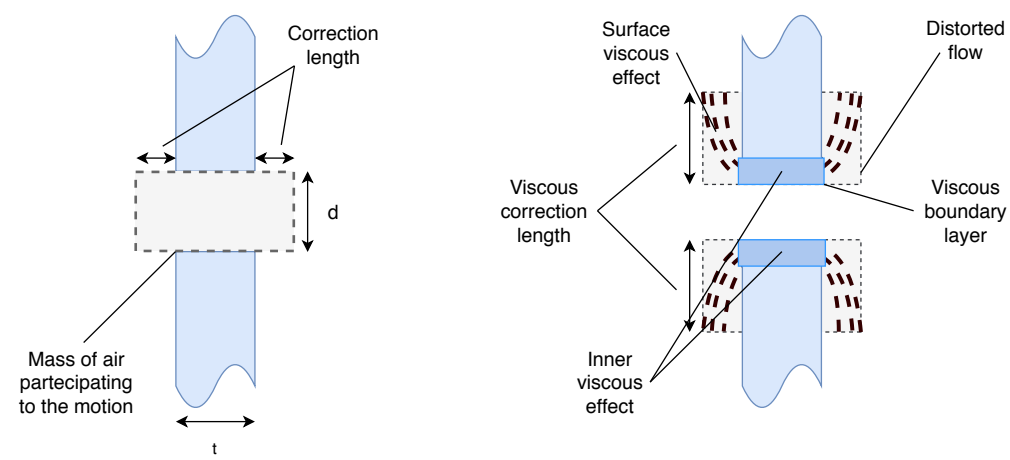

Figure 4. Physical phenomena involved in an MPP: surface viscous effects and inner viscous effects.

The EF model introduces the effective density $\tilde{\rho}_{e}$, which considers viscous and inertial effects that govern the front face impedance, inside the perforations, defined as:

$$
\tilde{\rho_{e}}=\rho_{0}\left[1+\frac{\sigma \phi\left(1+\frac{4 \omega \rho_{0} \eta}{\sigma^{2} \phi^{2} r^{2}}\right)^{1 / 2}}{i \omega \rho_{0}}\right]
$$

where $\sigma$ is the flow resistivity, defined as $\sigma=\frac{8 \eta}{\phi r^{2}}$. Thus, the impedance of the holes can be rewritten as:

$$
Z_{\text {holes }}=i \omega \tilde{\rho_{e}} \frac{t}{\phi} \text {. }
$$

The edge effects are introduced in the EF model through the geometrical tortuosity $\alpha_{\text {inf. }}$. In this work, the definition of $\alpha_{\text {inf }}$ provided by Atalla and Sgard [12] is used, meaning that not only the intrinsic properties of the material and its micro-geometry but also the media in contact with the panel will be considered. In case of a panel radiating on both sides:

$$
\alpha_{\mathrm{inf}}=1+\frac{2 \epsilon_{e}}{t}
$$

where $t$ is the thickness of the panel, and $\epsilon_{e}=0.48 \sqrt{\pi r^{2}}(1-1.14 \sqrt{\phi})$ (valid when $\phi<0.4$ ). In the EF model, the tortuosity replaces the Fok function introduced in Maa's model [9]. Thus, the panel impedance for a SL-MPP using the EF model is:

$$
\begin{gathered}
Z_{M P P, E F}=i \frac{\omega \rho_{0} \alpha_{\mathrm{inf}} t}{\phi}\left[1+\frac{\sigma \phi}{i \omega \rho_{0} \alpha_{\mathrm{inf}}}\left(1+i \frac{4 \omega \rho_{0} \alpha_{\mathrm{inf}}^{2} \eta}{\sigma^{2} \phi^{2} r^{2}}\right)^{1 / 2}\right] \\
Z_{1, E F}=Z_{M P P, E F}+Z_{c}
\end{gathered}
$$


A double-layer MPP system can be studied with the EF model as well, defining for the second layer of the MPP structure $Z_{M P P 2, E F}$ as:

$$
\begin{gathered}
Z_{M P P 2, E F}=i \frac{\omega \rho_{0} \alpha_{\mathrm{inf}, 2} t_{2}}{\phi_{2}}\left[1+\frac{\sigma_{2} \phi_{2}}{i \omega \rho_{0} \alpha_{\mathrm{inf}, 2}}\left(1+i \frac{4 \omega \rho_{0} \alpha_{\mathrm{inf}, 2}^{2} \eta}{\sigma_{2}^{2} \phi_{2}^{2} r_{2}^{2}}\right)^{1 / 2}\right] \\
Z_{2, E F}=Z_{M P P 2, E F}+Z_{c 2}
\end{gathered}
$$

Additionally, as done earlier with the Maa model, the entire double-layer surface impedance $Z_{1, E F}$ is obtained as follows:

$$
Z_{E F}=Z_{1, E F}+Z_{0} \frac{Z_{2, E F} \cos \left(k D_{2}\right)+i Z_{0} \sin \left(k D_{1}\right)}{Z_{0} \cos \left(k D_{1}\right)+i Z_{2, E F} \sin \left(k D_{2}\right)} .
$$

\section{MPP Samples}

The theoretical models have been used as a reference to design and develop different samples of micro-perforated panels. The purpose was to find the best configurations of the double-layer MPP's parameters in order to predict and simulate the behavior of sound absorbing structures that match the characteristic curve of speech, in view of the application to an university lecture hall.

\subsection{Samples Manifacturing}

The first step for the realization of an MPP layer was the material choice and, consequently, the standard thickness of the samples. Taking into consideration the sub-millimeter perforation diameter and the high quality standard in terms of durability and endurance, the choice was stainless steel. The aim was to obtain six samples with circular cross-sections and a diameter of $\sim 40 \mathrm{~mm}$ in order to allow the measurements in the impedance tube according to the technical standard ISO 10534-2 [26]. These three types of samples allowed to obtain different combinations between different samples, including double-layer structures with two equal samples. Considering the required perforation size $(<1 \mathrm{~mm})$ and geometry (circular cross-section), the stainless steel samples were manufactured using a 3D additive printing technique. A 316 grade stainless steel powder was used, specific for laser powder bed fusion (LPBF). The 3D printing process parameters are reported in Table 1.

Table 1. 3D printing process parameters. LPBF, laser powder bed fusion.

\begin{tabular}{cc}
\hline Parameter & Value \\
\hline Stainless steel powder grade & $316 \mathrm{~L}(\mathrm{LPBF})$ \\
Powder grains diameter & $30-40 \mu \mathrm{m}$ \\
Powder layer height & $60 \mu \mathrm{m}$ \\
Laser rated power & $360 \mathrm{~W}$ \\
Laser rated diameter & $50 \mu \mathrm{m}(\max 80 \mu \mathrm{m})$ \\
Energy density & $130 \mathrm{~J} / \mathrm{m}^{3}$ \\
Material specific weight & $7.98 \mathrm{~g} / \mathrm{cm}^{3}$ \\
\hline
\end{tabular}

This choice allowed us to print the three different types of samples in a single cylinder of stainless steel with a diameter of $\sim 40 \mathrm{~mm}$ and a height of $\sim 30 \mathrm{~mm}$ as shown in Figure 5, respecting the working restrictions of the printer. Once the stainless steel was printed, the problem was to find a specific cutting technique to make samples of $1 \mathrm{~mm}$ thickness. The only possible choice was to use a wire electrical discharge machining (WEDM). The WEDM technique works without increasing the heat during the cutting.

Thanks to this technique, two samples of each type were obtained from the cylinder. The thickness of each sample was respected with a tolerance of $\approx \pm 0.3-0.6 \mathrm{~mm}$, as shown in Figure 6.

Considering the scale of the perforation size, the real shapes of the perforations were not as expected and the real dimensions were bigger than expected: this was due to the 
limited accuracy of the processing and manufacturing machinery. Thus, all of the resulting perforations had irregular cross-sections: Ning et al. [29] demonstrated that increasing the specific surface area of a perforation could increase the sound energy dissipation and expand the sound absorption bandwidth, when the inscribed and circumscribed circle are assumed to be unchanged. In fact, keeping constant the outer diameter of the hole, an irregular cross-section increases the length of the hole perimeter and can add sharp edges; in this situation, viscous dissipation increases the sound absorption and the bandwidth.
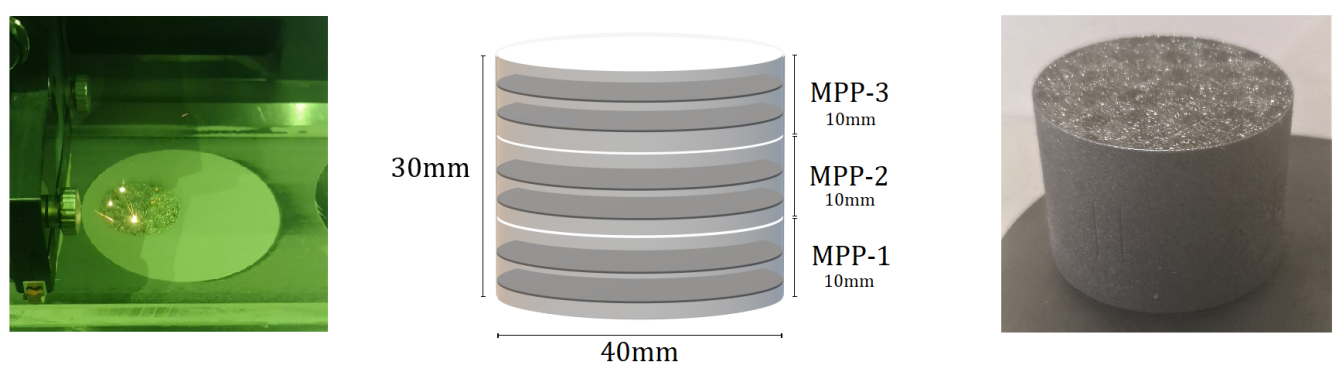

Figure 5. 3D metal printing (left); 3D sketch of the cylinder (center) and real photograph (right) of the cylinder. Two equal samples for three different kinds of specimen were obtained from the cylinder.
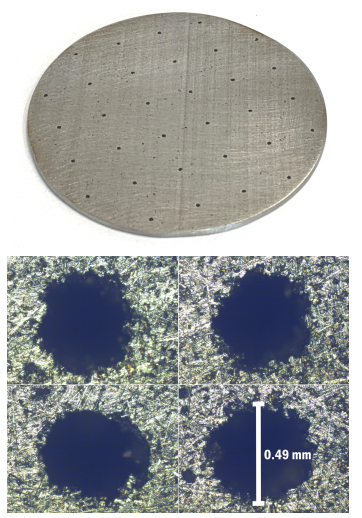
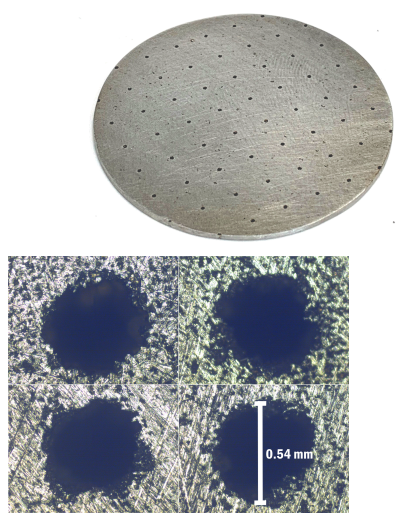
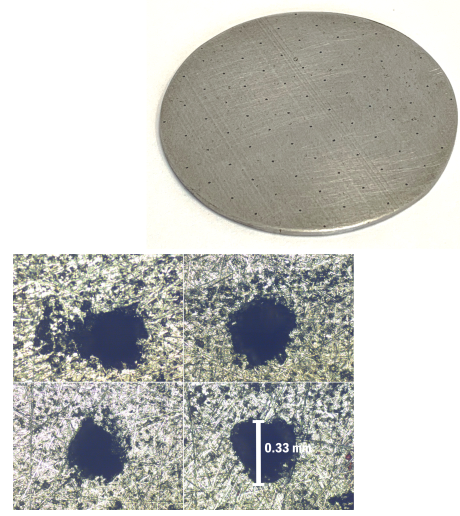

Figure 6. The three MPP samples (top) and the effective visualisation of perforations seen at the microscope (bottom).

\subsection{Measuring Equipment}

The use of the impedance tube with two microphone locations and a digital frequency analysis system for the determination of the sound absorption coefficient and acoustical surface impedance for normal sound incidence is shown in the standard ISO 10534-2 [26]. Considering a sample rate of $192 \mathrm{kHz}$ and the speed of sound in air at $T=18.6{ }^{\circ} \mathrm{C}$, $c_{0}=343 \mathrm{~m} / \mathrm{s}$, the effective dimensions of the tube were calculated and are reported in Figure 7.

The working frequency range of the impedance tube is 300-4400 Hz: the lower frequency is limited by the accuracy of the signal processing equipment; the upper frequency depends only on the physical dimensions of the tube. The measurements were made with the so-called one microphone method: recording the tube response using one microphone in two different locations. This choice eliminates phase mismatch between microphones. According to ISO 10534-2 [26], the transfer function method was developed in MATLAB [30], using the tube impedance measurements scripts of the ITA-Toolbox [31].

The measurement chain consisted of a loudspeaker for the signal generation, a power supply, an audio device working with the audio stream input output (ASIO) drivers, a microphone and a battery power signal conditioner, as reported in Table 2. 

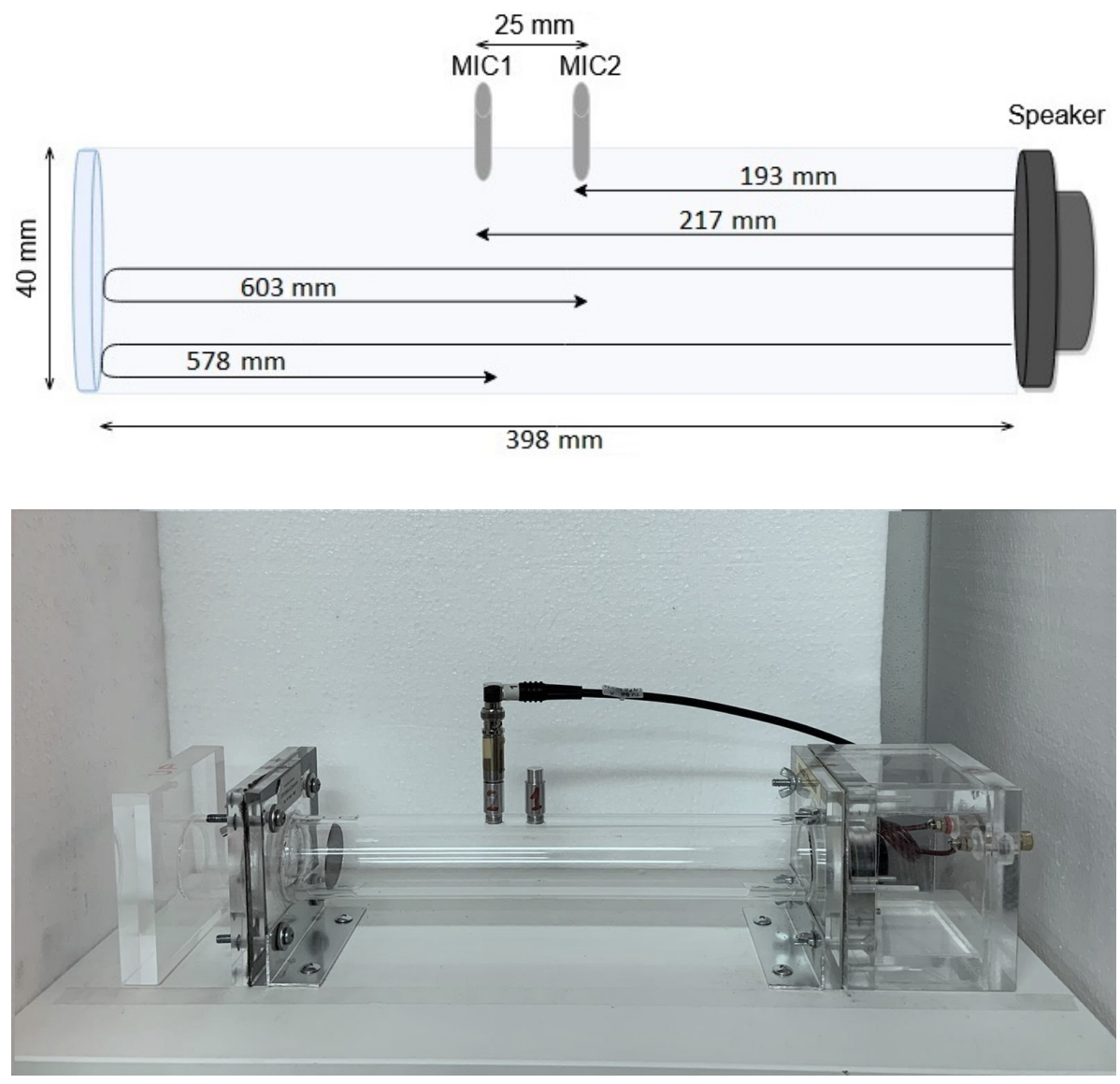

Figure 7. Effective dimensions (top) and actual photograph (bottom) of the impedance tube used in the ISO 10534-2 measurements.

Table 2. Equipment used for the impedance tube measurements.

\begin{tabular}{ccc}
\hline Device & Model & Specifics \\
\hline Microphone & PCB Piezoeletronics 130E20 & Free-Field, 20-10 k Hz \\
Loudspeaker & SICA Z000795 & 200-10 k Hz \\
Signal Conditioner & PCB Piezoeletronics 480B21 & Output Current 3 mA \\
Signal Amplifier & Tracopower TXL 100-125 & SNR $=96 \mathrm{dBS} / \mathrm{N}$ \\
Soundcard & RME Fireface 800 & Sample Rate $44,100 \mathrm{~Hz}$ \\
Software & MATLAB R2019a & ITA-Toolbox scripts \\
\hline
\end{tabular}

The output signal is an exponential sweep [32] converted to an analog signal by the digital-to-analog converter (DAC) of the audio device. The exponential sine sweep used for the experimental measurements was in the range of $250-5280 \mathrm{~Hz}$, according to the working frequency range of the impedance tube $(300-4400 \mathrm{~Hz})$. The signal pressure coming from the microphone was converted to a digital audio object through an AD converter. All of the digital signal processing was developed in MATLAB with the help of the ITA-Toolbox impedance tube calculation scripts. The schematic is reported in Figure 8.

The recorded audio file of length $2.97 \mathrm{~s}$ was sampled with a sample rate of $44,100 \mathrm{~Hz}$ at 24-bit depth, and a time data file of 131,072 samples was obtained. 


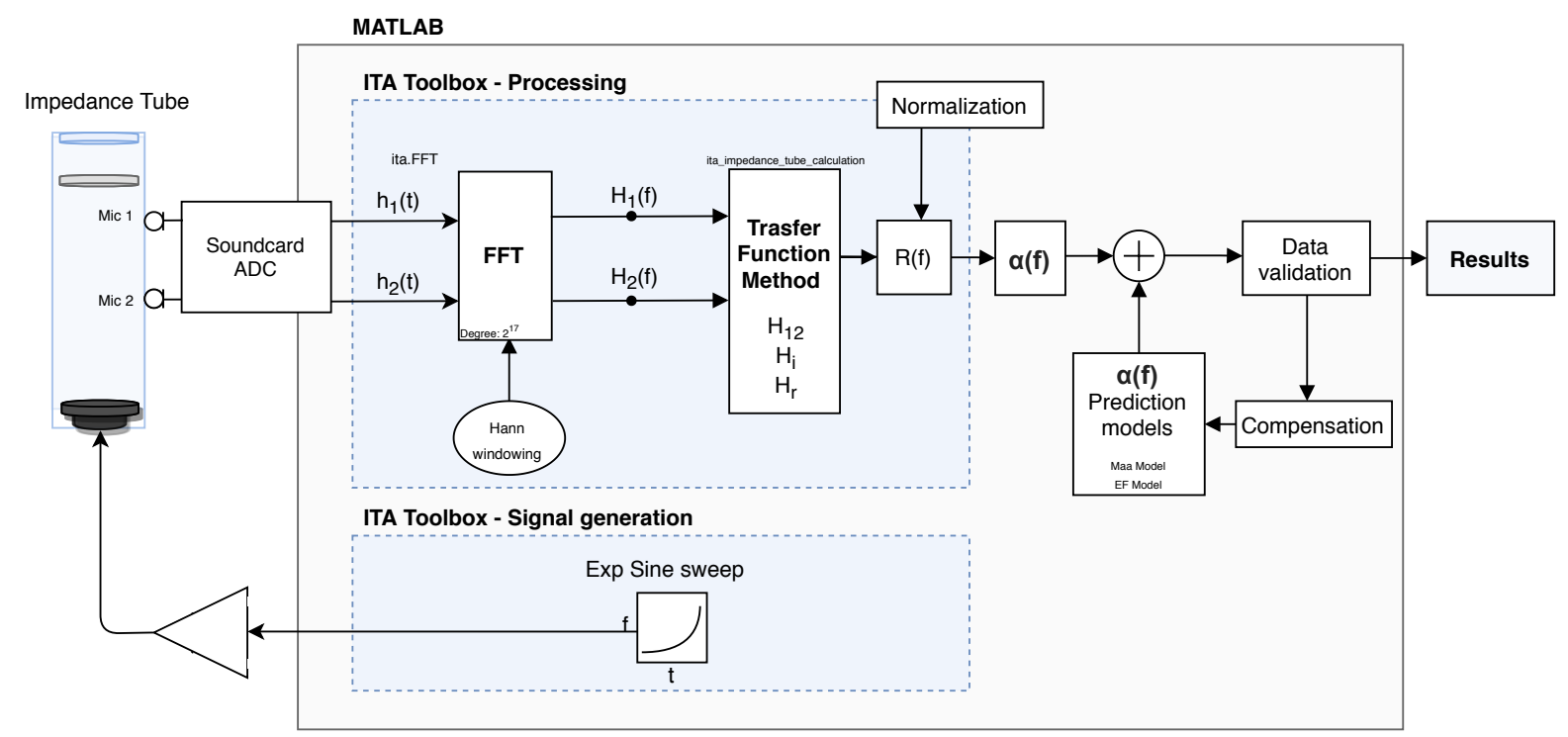

Figure 8. Data flow: excitation signal generation, acquisition of the impulse responses $h_{1}(t)$ and $h_{2}(t)$, processing, comparison with models, output of results.

\subsection{Models Compensation}

The experimental results for the MPP configurations showed some discrepancies between the measured data and both theoretical models decribed in Section 2. There were two important differences in common for each configuration:

- A small frequency shift of the sound absorption peaks;

- Absorption bandwidths larger than expected.

The first issue is connected to the samples' mounting procedure (Figure 9).
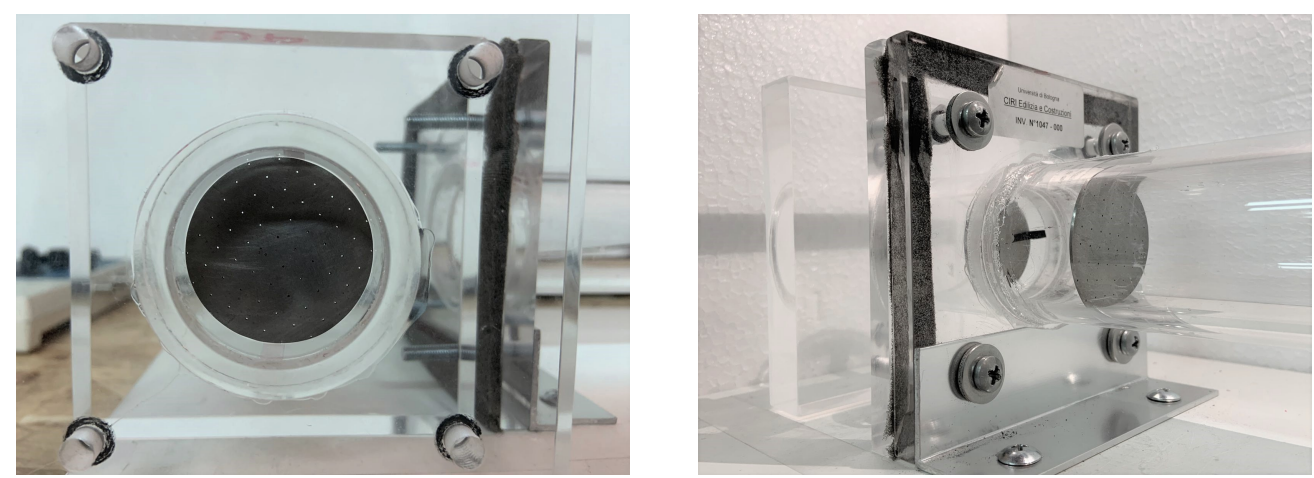

Figure 9. Details of the sample MPP02 mounted inside the impedance tube.

All samples were rounded and had a diameter slightly smaller than the sample holder. This did not guarantee the samples to be firmly mounted inside the tube. In order to avoid the side gaps between the specimen and the tube and to respect the mechanical boundary conditions, small strips of adhesive tape were applied to clamp the edges as much as possible. This caused small vibrations of the samples and a part of the energy was dissipated through the adhesive strips, increasing the absorption bandwidth.

The absorption bandwidth is due to the variability of the geometrical parameters of the samples: mainly, the irregular shapes and sizes of the perforations are the reasons why the measured data bandwidths appear to be larger than the predicted ones [33,34]. In particular, the smaller the perforations were, the bigger were the discrepancies. The perforations perimeter was larger than expected and, consequently, a bigger absorption bandwidth occured. Instead of acting on the sample mounting procedure, a new compensating impedance has been added to the models, taking into consideration the discrepancies. 
Considering the electro-acoustic analogy of the single-layer MPPs, the following changes were applied:

- $\quad R_{\text {comp }}$, a resistance in series with the MPP impedance, associated to the dissipative losses due to the irregular perforations;

- $\quad L_{c o m p}$, a new inductance in parallel with the MPP surface impedance, associated with the displacement of air along the boundary of the sample and the sample vibration [35].

This is still valid for the double-layer configurations: furthermore, the mounting inaccuracy is emphasized by the doubling of the MPP layer. In a DL configuration, two different resistances in series with the MPP impedance and two inductances in parallel with the MPP impedances have been considered, one for every MPP layer. Thus, in order to consider the geometrical dimension issues of the steel samples and the main problem connected to the sample mounting procedure, some changes to the equivalent circuits were made, as shown in Figure 10.
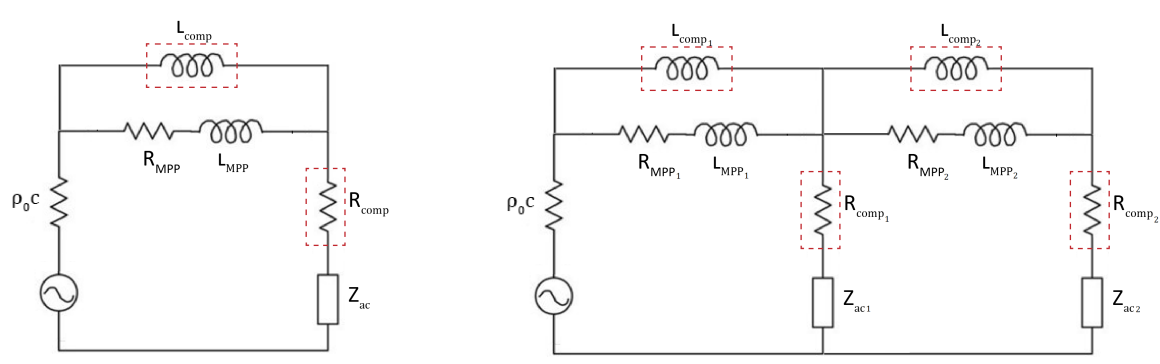

Figure 10. Electro-acoustical equivalent circuit for SL-MPP and DL-MPP configurations: the inductance $L_{c o m p}$ is in parallel with the MPP surface impedance $Z_{M P P}$, and the resistance $R_{\text {comp }}$ is in series with $Z_{M P P}$.

The explicit equation of the surface impedance in the case of a DL-MPP configuration after compensation is the following:

$$
\begin{gathered}
Z_{1, E F, \text { comp }}=\left(Z_{M P P 1, E F} L_{c o m p, 1}\right) /\left(Z_{M P P 1, E F}+L_{c o m p, 1}\right)+R_{c o m p, 1}+Z_{c} \\
Z_{2, E F, \text { comp }}=\left(Z_{M P P 2, E F} L_{c o m p, 2}\right) /\left(Z_{M P P 2, E F}+L_{c o m p, 2}\right)+R_{c o m p, 2}+Z_{c} \\
Z_{E F, \text { comp }}=Z_{1, E F, \text { comp }}+Z_{0} \frac{Z_{2, E F, \operatorname{comp} p} \cos \left(k D_{2}\right)+i Z_{0} \sin \left(k D_{1}\right)}{Z_{0} \cos \left(k D_{1}\right)+i Z_{2, E F, \text { comp }} \sin \left(k D_{2}\right)}
\end{gathered}
$$

In the present work, the values of $R_{\text {comp }}$ and $L_{\text {comp }}$ for the DL-MPP combinations were estimated by trial and error, trying to match the experimental data.

\subsection{Specimen Properties}

Three different SL configurations were measured, one for every type of sample (MPP01, MPP02, MPP03). A different value of the air cavity thickness was chosen for every MPP sample, in order to obtain a good sound absorption peak around $1000 \mathrm{~Hz}$. The same was done for four different DL configurations, composed of the type of samples mentioned above. Two layers of MPP provide two different resonance peaks: the choice was to try to find DL configurations with an absorption peak at $1000 \mathrm{~Hz}$ and a second peak in a lower frequency range. The three samples had the effective geometrical parameters reported in Table 3.

The comparison between the equivalent fluid model and the experimental measurements is reported in terms of sound absorption coefficient and normalized surface impedance in Figure 11 for three SL configurations.

The three samples were used in four different combinations of DL configurations with air cavities reported in Table 4, and a comparison was made between the EF model and the experimental measurements in terms of sound absorption coefficient and normalized 
surface impedance in Figure 12. In contrast to the SL comparisons, the DL experimental measurements showed bigger discrepancies from the model: this is due to the mounting procedure inaccuracies and the irregular perforations of two different samples, both doubled. The model compensation is not enough to completely compensate for the nonidealities, mainly in terms of normalized surface impedance.

Table 3. Expected (exp.) and effective (eff.) geometrical parameters of the three MPP specimens.

\begin{tabular}{ccccccc}
\hline \multirow{2}{*}{ Specimen } & \multicolumn{2}{c}{ MPP01 } & \multicolumn{2}{c}{ MPP02 } & \multicolumn{2}{c}{ MPP03 } \\
\cline { 2 - 7 } & Exp. & Eff. & Exp. & Eff. & Exp. & Eff. \\
\hline Thickness (mm) & 1 & $0.94 \pm 0.03$ & 1 & $0.95 \pm 0.01$ & 1 & $0.92 \pm 0.02$ \\
Porosity (\%) & 0.5 & 0.5 & 1 & 1 & 0.5 & 0.5 \\
Perforation & 0.5 & $0.483 \pm 0.04$ & 0.5 & $0.482 \pm 0.03$ & 0.3 & $0.33 \pm 0.05$ \\
diameter (mm) & & & & & \\
\hline
\end{tabular}
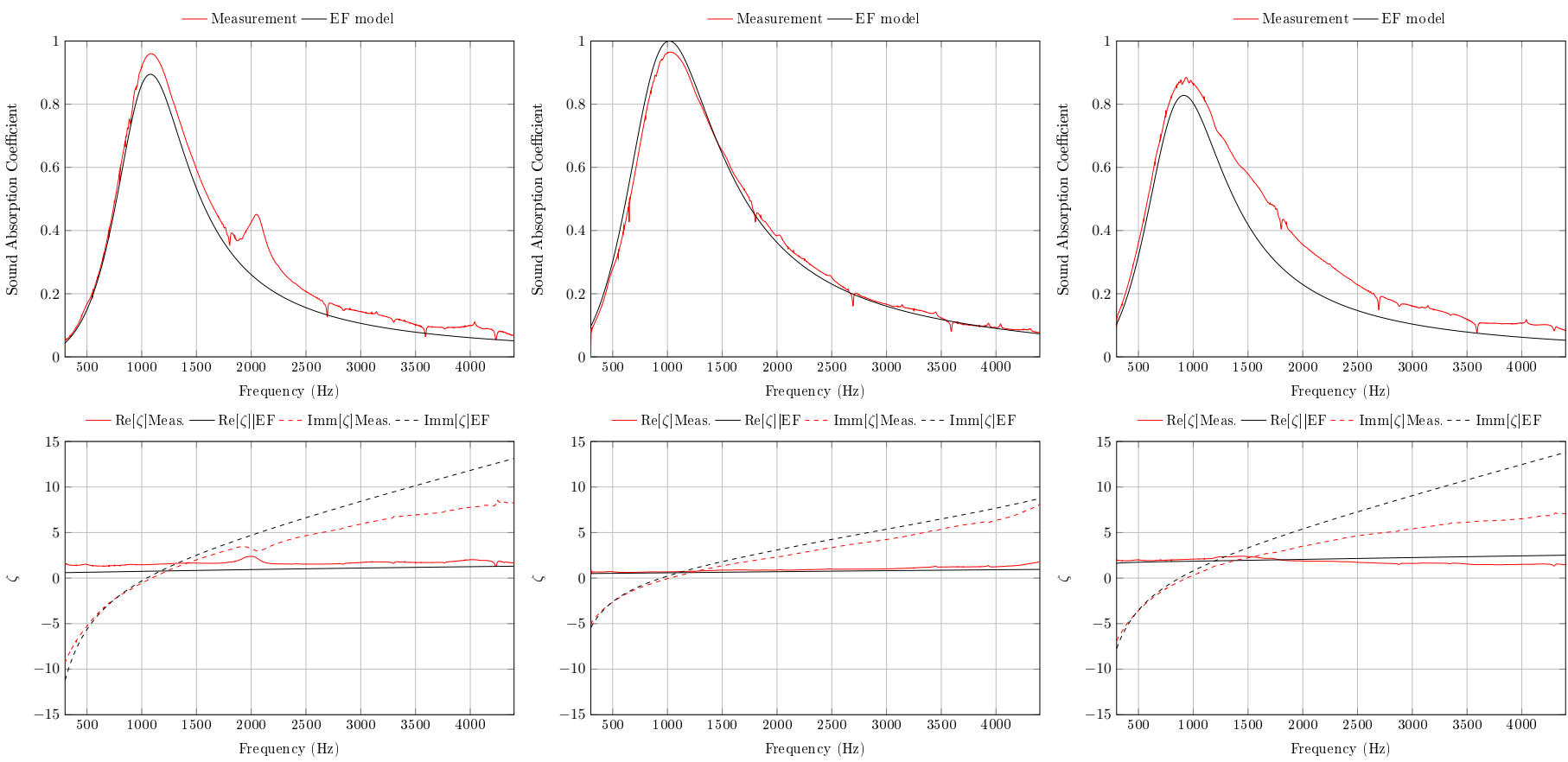

Figure 11. Sound absorption coefficient and normalized surface impedance of single-layer MPPs: MPP01 with an air cavity of $D=14.8 \mathrm{~mm}$, MPP02 with an air cavity of $D=30 \mathrm{~mm}$ and MPP03 with an air cavity of $D=20 \mathrm{~mm}$.

Table 4. Specific normalised impedances corresponding to the four double-layer configurations. Octave band data were fitted based on the outcomes of the compensation model described in the text.

\begin{tabular}{|c|c|c|c|c|c|c|c|c|c|c|}
\hline & \multirow{2}{*}{ 1st Layer } & \multirow{2}{*}{$\begin{array}{c}\text { 1st Cav. } \\
\text { mm }\end{array}$} & \multirow{2}{*}{ 2nd Layer } & \multirow{2}{*}{$\begin{array}{l}\text { 2nd Cav. } \\
\qquad \mathrm{mm}\end{array}$} & \multicolumn{6}{|c|}{$\zeta$} \\
\hline & & & & & $125 \mathrm{~Hz}$ & $250 \mathrm{~Hz}$ & $500 \mathrm{~Hz}$ & $1 \mathrm{kHz}$ & $2 \mathrm{kHz}$ & $4 \mathrm{kHz}$ \\
\hline A & MPP01 & 40 & MPP01 & 30 & $1.3-16.4 i$ & $1.3-6.8 i$ & $1.8-0.9 i$ & $2.2+2.0 i$ & $1.6+8.4 i$ & $4.4+a i$ \\
\hline B & МРP01 & 50 & MPP02 & 50 & $1.4-12.3 i$ & $1.5-4.9 i$ & $1.9-0.1 i$ & $2.5+2.7 i$ & $1.8+9.0 i$ & $3.1-a i$ \\
\hline C & MPР02 & 45 & МРP03 & 45 & $0.4-14.2 i$ & $0.4-6.2 i$ & $0.7-1.4 i$ & $1.7-0.4 i$ & $0.5+3.5 i$ & $1.8+8.5 i$ \\
\hline $\mathrm{D}$ & MPP01 & 35 & МРР03 & 35 & $1.4-18.1 i$ & $1.4-7.7 i$ & $1.5-1.6 i$ & $3.1+2.3 i$ & $1.8+7.5 i$ & $2.1+15.7 i$ \\
\hline
\end{tabular}

$a \rightarrow \infty$ : the function diverges to infinity or minus infinity. 

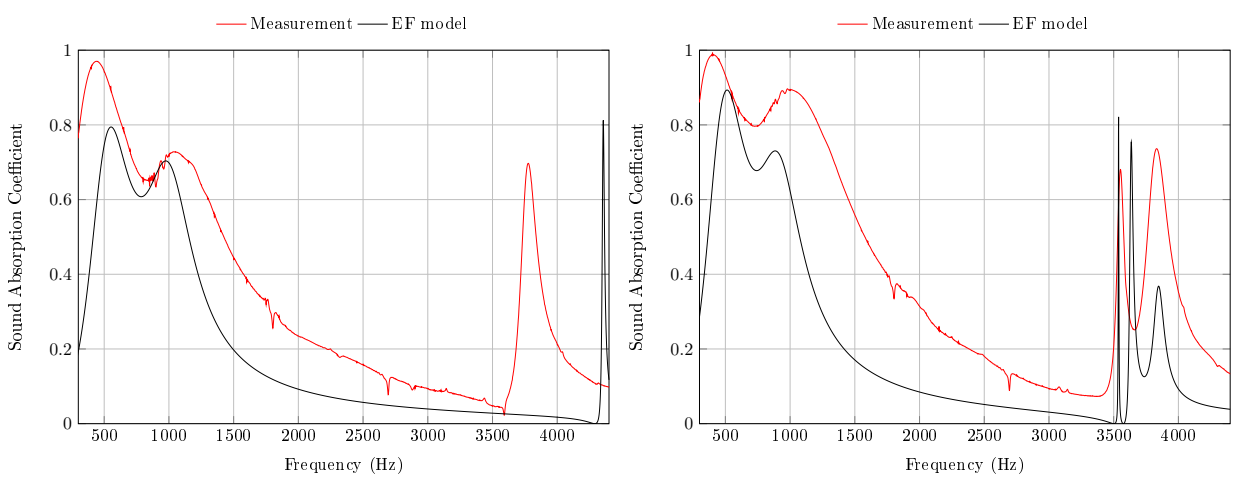

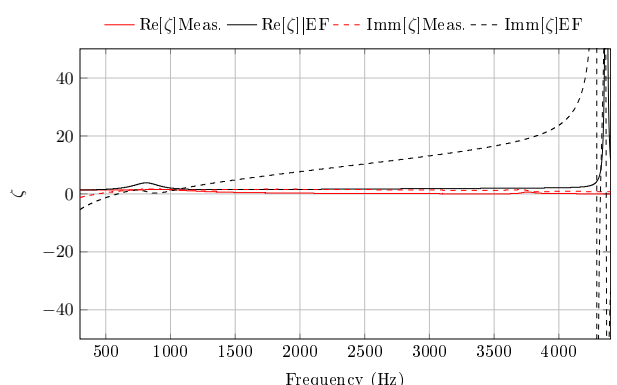

(a)
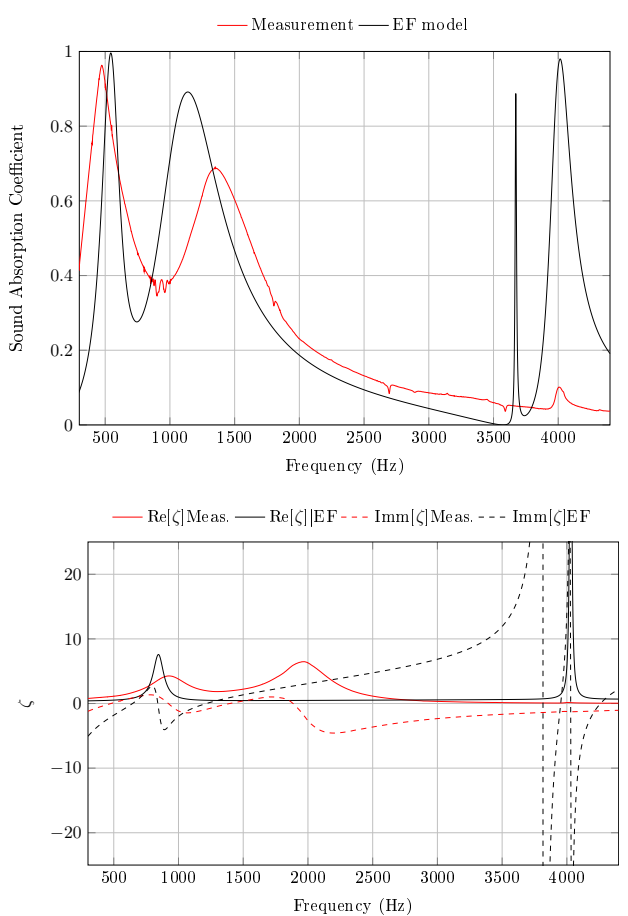

(c)

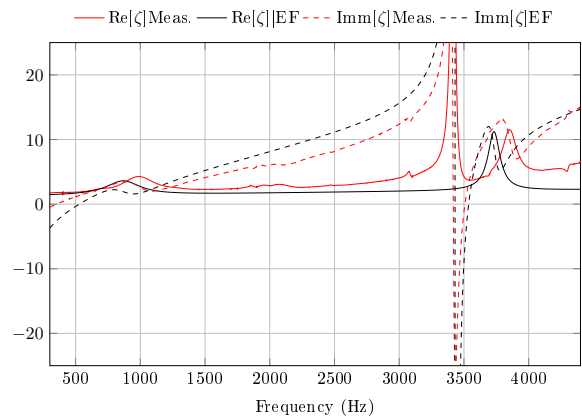

(b)
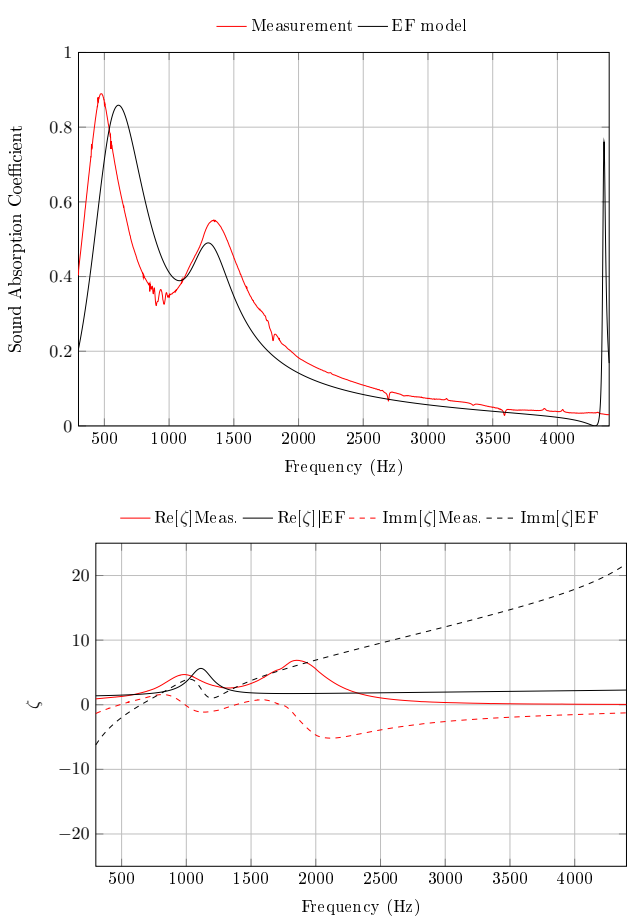

(d)

Figure 12. Sound absorption coefficient and normalized surface impedance for four DL configurations. (a) Configuration A. (b) Configuration B. (c) Configuration C. (d) Configuration D.

\section{Finite-Difference Time-Domain Simulations}

In room acoustics, multiple simulation methods aim to directly solve the wave equation in homogeneous form:

$$
\left(\nabla^{2}-\frac{1}{c_{0}^{2}} \frac{\partial^{2}}{\partial t^{2}}\right) p=0
$$


where $\nabla^{2}$ is the 3D Laplacian operator, $c_{0}$ is the speed of sound at $T=20^{\circ} \mathrm{C}$ and $\mathrm{RH}=50 \%$, and $p=p(\mathbf{x}, t)$ is the pressure (deviation from ambient). The finite-difference time-domain (FDTD) method is among the oldest numerical methods to solve time-dependent partial differential equations (PDEs), like the wave equation [36]. In FDTD methods, space and time continuous domains are typically discretized with regular Cartesian grids and updating recursions occur in the nodal points to calculate the acoustic properties such as the pressure $p(\mathbf{x}, t)$ or the particle velocity potential $u(\mathbf{x}, t)$ [37]. The solution $p(\mathbf{x}, t)$ of the wave equation, with $\mathbf{x} \in \mathbb{R}^{3}$, is approximated by a grid function $p_{l, m, p}^{n}$ at spatiotemporal points $x=l h, y=m h, z=p h$ and $t=n k$, with $l, m, n$ and $p$ representing integer numbers, $h$ the grid spacing, and $k$ the time step $[38,39]$. A large variety of explicit FDTD methods follows the same general scheme:

$$
\delta_{t}^{2} p_{l, m, p}^{n}=\lambda^{2}\left[\left(\delta_{x}^{2}+\delta_{y}^{2}+\delta_{z}^{2}\right)+a\left(\delta_{x}^{2} \delta_{y}^{2}+\delta_{x}^{2} \delta_{z}^{2}+\delta_{y}^{2} \delta_{z}^{2}\right)+b\left(\delta_{x}^{2} \delta_{y}^{2} \delta_{z}^{2}\right)\right] p_{l, m, p}^{n}
$$

where $\lambda$ is the dimensionless quantity defined as the Courant number $\lambda=c k / h$ and $a$ and $b$ are the specific coefficients of a general family of compact explicit schemes [40]. The operators $\delta_{t}^{2}$ and $\delta_{x}^{2}$ act on $p_{l, m, p}^{n}$ as follows:

$$
\delta_{t}^{2} p_{l, m, p}^{n}=p_{l, m, p}^{n+1}-2 p_{l, m, p}^{n}+p_{l, m, p^{\prime}}^{n-1} \quad \delta_{x}^{2} p_{l, m, p}^{n}=p_{l+1, m, p}^{n}-2 p_{l, m, p}^{n}+p_{l-1, m, p}^{n}
$$

and similarly for $\delta_{y}^{2}$ and $\delta_{z}^{2}$. The value of the Courant number is closely correlated to the stability condition of the system, which is guaranteed avoiding the exponential growth of the numerical solution (see, e.g., [41]). In the simple case of the seven-point scheme $(a=b$ $=0)$, the stability condition is expressed as:

$$
\lambda \leq \frac{1}{\sqrt{3}}
$$

which is the so-called Courant-Friedrichs-Lewy (CLF) condition [36].

However, in this paper the cubic close-packed (CCP) scheme (see Figure 13), with $a=$ $0.25, b=0$ and $\lambda=1$, is employed for its favorable numerical dispersion properties [41]. The consequent maximal time step, for a certain grid spacing, is $k<\mathrm{h} / \mathrm{c}$. As is the case for any 3D FDTD scheme, the computational cost is proportional to $h^{-3}$, which can quickly lead to large simulation grids. Then, such grid-based simulations are natural candidates for parallel acceleration on graphics processing units (GPUs) [42].
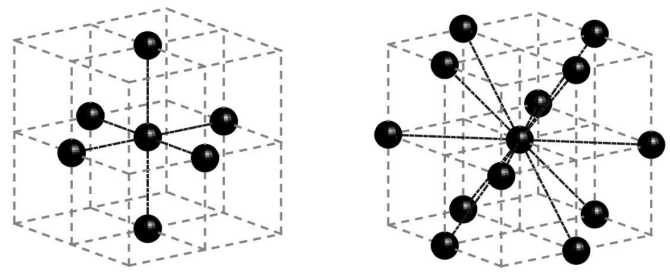

Figure 13. Two possible stencils: standard 7-point (left) and cubic close-packed (CCP) 13-point (right). Image credit: see reference [28].

\section{Application in a Case Study: Use of MPPs as a Ceiling Acoustic Treatment}

A wide employment of sustainable materials such the multi-layer MPPs analyzed in this study is expected to occur in several typologies of enclosed environments [35,43], replacing or integrating the common sound absorbing treatments. MPP absorbers are theoretically expected to return the same acoustic behavior regardless of their constitutive material. Therefore, concerning sustainability aspects, they can be made of any green material, reducing the environmental footprint of the whole process. The acoustic simulation of a wide application in a 3D virtual enclosure is a useful tool in a preliminary step in the assessment of their performance [44-46]. 
With this purpose, the acoustic condition of a large university lecture hall has been simulated with a ceiling-mounted system of double-layer MPPs. Such a kind of large rooms shows the highest values of reverberation time at 500 and $1000 \mathrm{~Hz}$ (see Figure 4 in [27]), the same frequency range occupied by the human voice [47]. As too high values of reverberation time deteriorate speech intelligibility, a material whose sound absorbing properties are mostly centered in such a frequency range may return useful outcomes in acoustic treatments of existing university halls. Otherwise, an acoustic treatment with porous or fiber materials would provide the most significant absorbing contribution at higher frequencies [48], sometimes entailing too dry conditions at $2000 \mathrm{~Hz}$ and $4000 \mathrm{~Hz}$.

The room chosen as a case study is a historical lecture hall in the University of Bologna (see Figure 14). A previous campaign of acoustic measurements $[27,49]$ in the hall allowed to collect the main room criteria [50] and intelligibility indexes [47]. The setting of sound source and receiver locations chosen for the measurements campaign is also provided in Figure 14.

The 3D virtual model of the hall-about $900 \mathrm{~m}^{3}$ was built with Sketchup [51] according to consolidated approximation guidelines (see Figure 15), i.e., with a certain degree of geometrical approximation and with a proper division in macro-layers depending on the materials $[52,53]$. The 3D model was modeled using a small group of different materials (see Table 5) to reduce the uncertainties underlying the assignment of material properties to each surface. With regard to the absorption area distribution, it should be noted that, generally, the seats are the most sound absorbing objects in a lecture hall in unoccupied state [23,44-46]. The remaining layers of the model (walls, floor, ceiling) are made up of rather hard and reflective surfaces, and thus they show low values in the whole frequency range. It should also be highlighted that the random incidence absorption coefficients at low frequencies of wooden parts are due to the air cavity behind them (see dataset in Table 5).

The state-of-the-art procedure to simulate the sound field of a large lecture hall would imply the use of geometrical acoustics (GA) techniques [46,54]. Nevertheless, MPPs are not suitable to be characterized by the energy-based parameters, i.e., the absorption coefficients, usually involved in GA practice. Therefore, the need arose to simulate the acoustic behavior by using a wave-based algorithm, such as a FDTD model, that, additionally, assures the correct computation of the diffraction effects due to the objects' edges [55].
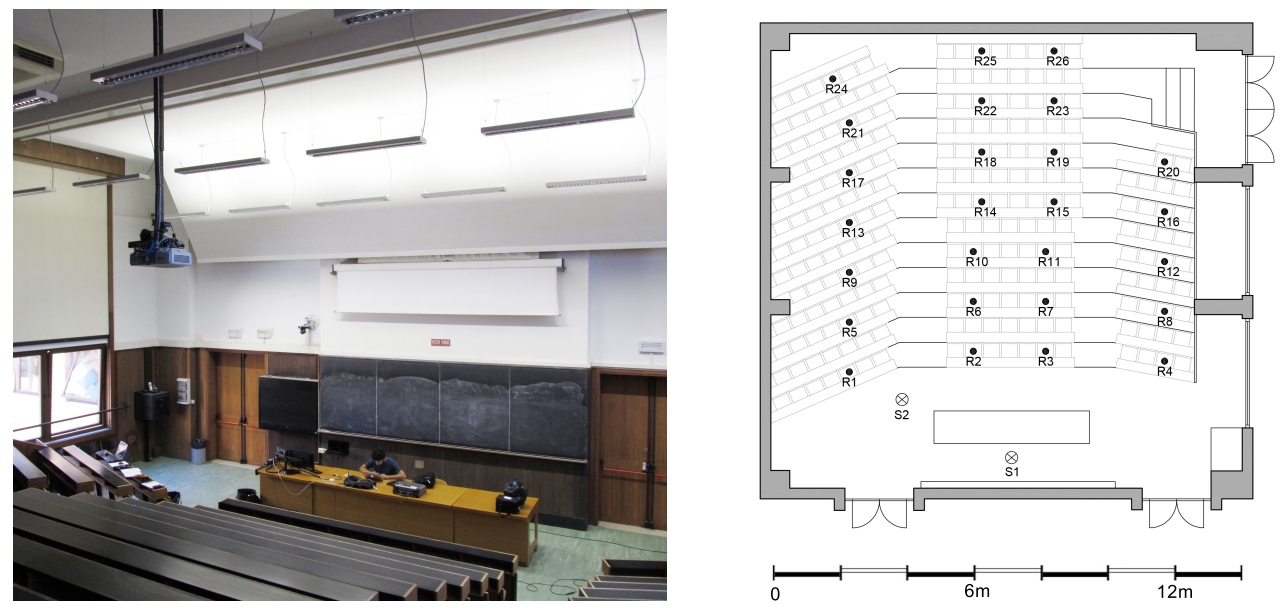

Figure 14. Interior view (left) and 2D plan (right) of the lecture hall under study. Sound sources (S1, S2) and the spatial grid of microphone receivers (R1, R2, .., RN) used in the measurements campaign are reported. 

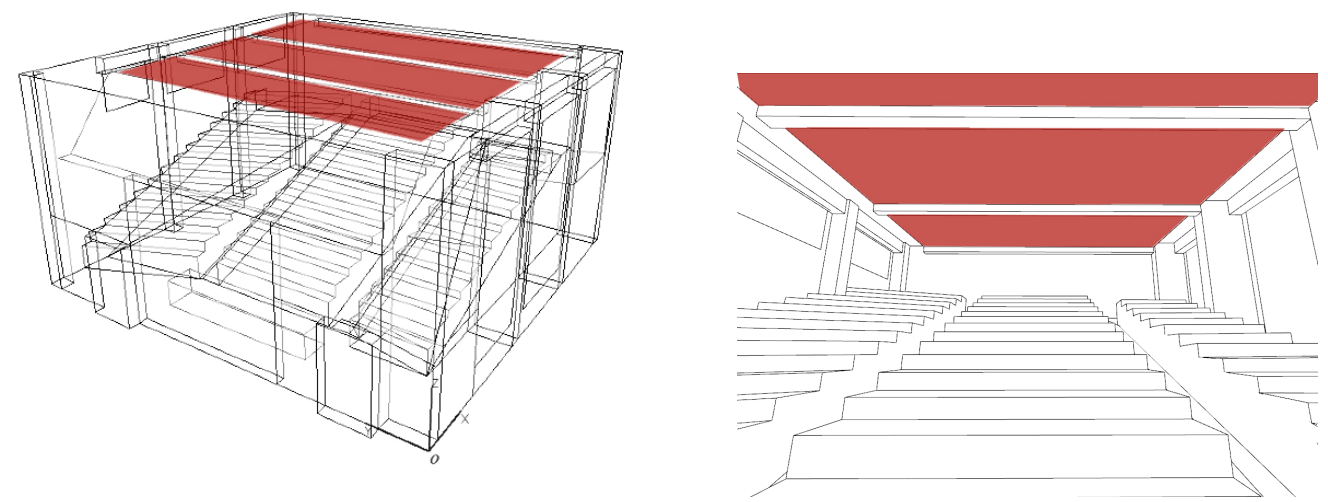

Figure 15. Exterior (left) and interior (right) view of the acoustic treatment virtually introduced into the CAD model. The ceiling-mounted MPPs are highlighted in red.

Table 5. Calibration setup (without MPP): random incidence absorption coefficients used in geometrical acoustics (GA) simulations and considered in the backward optimization process to obtain the acoustic admittances for the finite-difference time-domain (FDTD) simulation. The macro-layers used in the present work divide the materials into: hard/reflective surfaces (plaster floor), elements absorbing slightly at low frequencies (wood, windows) and the most sound absorbing area (seats).

\begin{tabular}{ccccccc}
\hline Materials & $\mathbf{1 2 5} \mathbf{H z}$ & $\mathbf{2 5 0} \mathbf{H z}$ & $\mathbf{5 0 0} \mathbf{H z}$ & $\mathbf{1 0 0 0} \mathbf{~ H z}$ & $\mathbf{2 0 0 0} \mathbf{H z}$ & $\mathbf{4 0 0 0} \mathbf{H z}$ \\
\hline Plaster & 0.01 & 0.02 & 0.03 & 0.03 & 0.04 & 0.06 \\
floor & 0.15 & 0.18 & 0.04 & 0.04 & 0.04 & 0.04 \\
Wood & 0.10 & 0.10 & 0.08 & 0.04 & 0.04 & 0.04 \\
Windows & 0.40 & 0.37 & 0.26 & 0.19 & 0.17 & 0.16 \\
Seats & & &
\end{tabular}

With this purpose, in the 3D virtual model the edges of the blocks containing the seats and the long tables were modeled (see Figure 16b). The contour map shows the edge diffraction due to the seats, which are typically the only irregular element in a lecture hall contributing to the sound field diffusion. Figure 16 also shows a qualitative comparison with the standard GA simulation that involves a simpler modeling of the seats' blocks and a scattering coefficient (see Figure 16a).

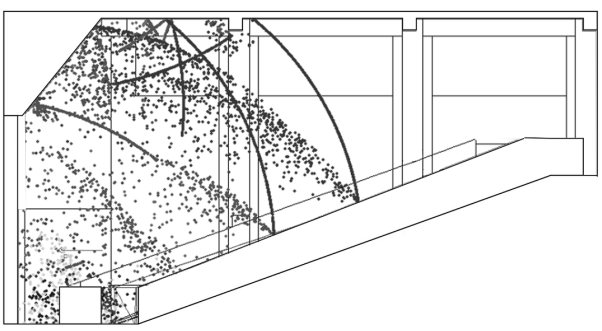

(a) GA

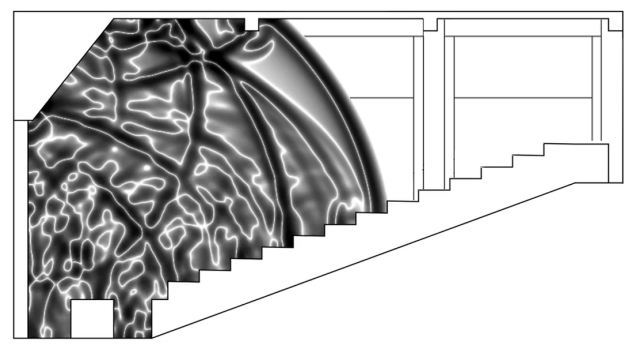

(b) FDTD

Figure 16. Qualitative visualization of sound wave propagation within the lecture hall by means of GA (a) and FDTD (b) simulations throughout the longitudinal section. The sound source is located at the teacher's position (S1 in Figure 14).

The DL-MPP corresponding to Configuration A in Table 4 was introduced in the model replacing most of the part of the existing false ceiling, as can be seen in Figure 15. Typically, the acoustic impedances needed as boundary conditions for an FDTD numerical simulation derive from the large amount of random incidence absorption coefficient datasets available through optimization processes [56]. Indeed, uncertainties inherent in energy parameters (absorption coefficients)—also due to ISO 354 limits [57]—are propagated in the conversion to non-unique corresponding complex acoustic impedances [58]. In this case, it has been 
possible to avoid some of those typical uncertainties in the workflow by directly starting with complex acoustic impedances values as input boundary conditions (see Figure 17) $[59,60]$.

Concerning the locally reactive absorption properties of the MPPs, the outcomes of the compensation model described in Section 3.3 were used to fit complex impedances to a boundary impedance model comprising a parallel network of second-order series RLC circuits [61]. The fitting procedure optimized non-negative circuit parameters (resistances, inductances and capacitances) in order to minimize the Euclidean norm of the error between the complex admittance of the circuit network and that of the data. A similar process was carried for known absorption coefficients of the remaining materials, following [62]. The complex admittance data and the model approximation to be used in the FDTD simulation are shown in Figure 17. As can be seen in the figure, the filter model described in $[61,62]$ and used in the FDTD simulation faithfully reproduced the complex admittance of the MPP material.
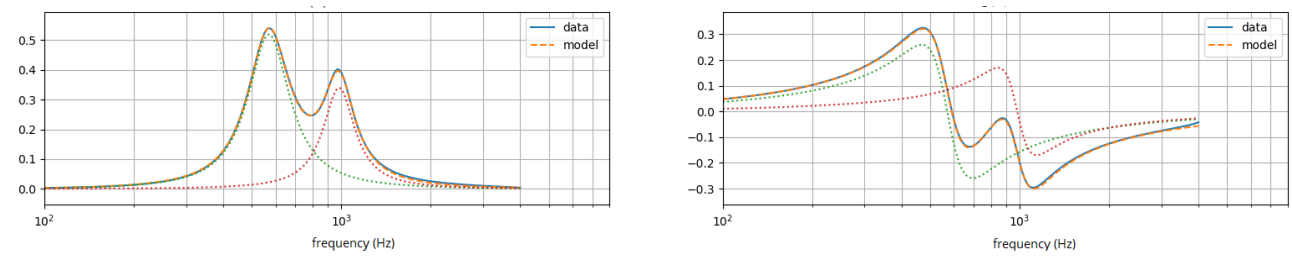

Figure 17. Real (left) and imaginary (right) parts of complex specific admittances from data for MPP material (solid line) along with fitted filter model (dashed line) used in the FDTD simulation. Dotted lines show underlying resonances in the filter approximation.

The FDTD method chosen simulated up to $8000 \mathrm{~Hz}$ with 6.75 points per wavelength (Cartesian grid spacing $h=6.35 \mathrm{~mm}$ and time step $k=18.5 \mu \mathrm{s}$ ), which required approximately $2 \mathrm{~h}$ per sound source using four Nvidia Titan X (Maxwell) GPUs. It should be noticed that even though the FDTD model chosen in this work can switch to a ray-tracing algorithm over a certain frequency [63], in this case it was possible to run a full wave-based simulation thanks to the moderate complexity of the geometry and the availability of high computational power.

Before introducing the double-layer MPP into the virtual model of the lecture hall, the calibration process was carried out based on the main room criteria acquired from the acoustic measurements. The 3D model was tuned in terms of reverberation time $\left(\mathrm{T}_{30}\right)$ considering the sound source in location $\mathrm{S} 1$ and averaging the values over all the receiver points shown in Figure 14. Table 6 reports the trend in frequency of the measured values, the equivalent values derived from the calibrated FDTD model ("without MPP") and the variations due to the introduction of MPPs ("with MPP"). During the tuning of the 3D model, the tolerance range for the discrepancies between measured and simulated values was kept equal to twice the common JND [50], considering $10 \%$ of the measured values according to recent remarks [64]. Table 6 also provides the $T_{30}$ mean values derived from the corresponding GA simulations to keep the comparison with the standard simulation procedure. Certainly in the GA model all of the temporal delays and acoustic behaviors due to the peculiarity of MPPs are approximated by energy parameters (absorption coefficients). With regard to the results in terms of reverberation time, the main contribution of the acoustic treatment is relevant at $500-1000 \mathrm{~Hz}$, as expected, and still significant at 250 and $2000 \mathrm{~Hz}$, due to the broadband performance obtained with DL configurations. The effects of treating a lecture hall with such a material instead of a common porous material are positive not only because they cover the frequency range occupied by the human voice, but also because they compensate for the typical excessive reverberation that undermines the verbal communication in historical rooms. 
Table 6. Trend in frequency of $\mathrm{T}_{30}$ mean values corresponding to the results of the measurements ("Meas"), the equivalent values derived from the calibrated FDTD model ("without MPP") and the variations due to the introduction of MPPs ("with MPP"). The $\mathrm{T}_{30}$ mean values derived from the corresponding GA simulations are provided as a term of comparison.

\begin{tabular}{|c|c|c|c|c|c|c|}
\hline $\mathrm{T}_{30}(s)$ & $125 \mathrm{~Hz}$ & $250 \mathrm{~Hz}$ & $500 \mathrm{~Hz}$ & $1000 \mathrm{~Hz}$ & $2000 \mathrm{~Hz}$ & $4000 \mathrm{~Hz}$ \\
\hline Without MPP (Meas.) & 1.48 & 1.36 & 1.60 & 1.84 & 1.83 & 1.51 \\
\hline Without MPP (FDTD) & 1.44 & 1.25 & 1.54 & 1.73 & 1.70 & 1.45 \\
\hline Without MPP (GA) & 1.43 & 1.25 & 1.62 & 1.79 & 1.78 & 1.52 \\
\hline With MPP (FDTD) & 1.32 & 0.92 & 0.88 & 1.22 & 1.52 & 1.44 \\
\hline With MPP (GA) & 1.33 & 1.06 & 0.87 & 1.00 & 1.34 & 1.50 \\
\hline
\end{tabular}

Concerning the room criteria related to intelligibility, it is quite intuitive that in an optimal condition for the verbal communication their values should be as uniform as possible throughout the space. Therefore, the spatial behavior of sound clarity $\left(\mathrm{C}_{50}\right)[50]$ is provided versus the distance between the source and the receiver (see Figure 18). The same five conditions already seen in Table 6 are reported in the graph: the measured values, the calibration outcomes and the effects of the acoustic treatment according to FDTD and GA results. On average, it is possible to quantify an increase of $\mathrm{C}_{50}$ values at mid frequencies higher than $4 \mathrm{~dB}$, corresponding to four times the JND of the sound clarity. The acoustic treatment allowed to significantly increase the early-to-late ratio $\left(\mathrm{C}_{50, \mathrm{M}} \approx 2 \mathrm{~dB}\right)$ from a poor acoustic condition $\left(\mathrm{C}_{50, \mathrm{M}} \approx-2.5 \mathrm{~dB}\right)$. Figure 18 also shows a good match among all the slopes of the linear regressions involved. This is probably due to the fact that the calibration was achieved by using an energy parameter, the reverberation time, that is derived from the energy decay curve as the sound clarity.

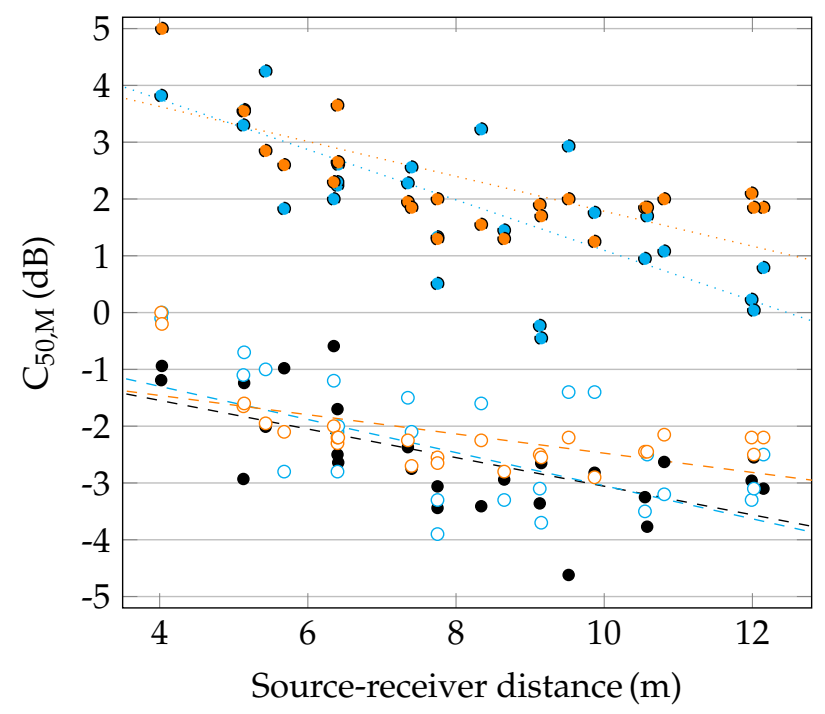

• w/o MPP (Meas.) ○ w/o MPP (FDTD) ○ w/o MPP (GA) o w MPP (FDTD) o w MPP (GA)

Figure 18. Trend of sound clarity $\left(\mathrm{C}_{50}\right)$ as a function of the sound source-receiver distance (values and linear regressions). " $\mathrm{M}$ " indicates that the values have been averaged over 500 and $1000 \mathrm{~Hz}$. Results of the measurements ("Meas"), the equivalent values derived from the calibrated FDTD model ("w/o MPP") and the variations due to the introduction of MPPs ("w MPP") are provided by using both FDTD and GA techniques.

Finally, an overview is provided about other recent works that handle the microperforated panels with wave-base simulation methods. Table 7 helps to place the present work in a framework of similar research studies to highlight similarities and methodological differences. Concerning the boundary conditions, it should be highlighted that only in reference [65] an extended reaction model for SL-MPP absorbers was used, including the 
incident angle dependence of surface impedance. In references [66,67] and in the present work the local reaction is assumed. To the best of the authors' knowledge, at the time of writing there are several issues in handling extended reaction in FDTD and concurrently keeping the stability of the system. Indeed, in future developments further efforts will be made to improve the locally reactive simplified model used in the present work with the angle-dependent model.

Table 7. Framework of recent works focused on wave-based simulations of micro-perforated panels. The frequency range managed by the authors, the calculation method, the typology of boundary condition employed and the output parameters obtained are reported.

\begin{tabular}{|c|c|c|c|c|}
\hline Reference & $\begin{array}{c}\text { Range } \\
(\mathrm{Hz})\end{array}$ & $\begin{array}{l}\text { Calculation } \\
\text { Method }\end{array}$ & $\begin{array}{l}\text { Boundary } \\
\text { Condition }\end{array}$ & Output \\
\hline $\begin{array}{l}\text { Liu and Herrin, } \\
2010 \text { [68] }\end{array}$ & $100-5000$ & BEM & $\begin{array}{l}\text { Transfer } \\
\text { Impedance }\end{array}$ & $\begin{array}{c}\text { SPL, } \\
\text { Insertion Loss }\end{array}$ \\
\hline $\begin{array}{c}\text { Okuzono and } \\
\text { Sakagami, } \\
2015 \text { [66] }\end{array}$ & $30-6000$ & FEM & $\begin{array}{c}\text { Surface } \\
\text { Impedance }\end{array}$ & 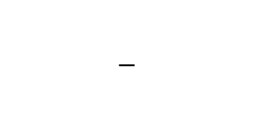 \\
\hline $\begin{array}{l}\text { Okuzono and } \\
\text { Sakagami, } \\
2018 \text { [65] }\end{array}$ & $125-1000$ & FEM & $\begin{array}{c}\text { Surface } \\
\text { Impedance }\end{array}$ & $\mathrm{T}_{30}, \mathrm{SPL}$ \\
\hline $\begin{array}{c}\text { Naderyan et al., } \\
2019 \text { [69] }\end{array}$ & $710-1400$ & FEM & $\begin{array}{c}\text { Surface } \\
\text { Impedance }\end{array}$ & $\begin{array}{l}\text { Power dissipa- } \\
\text { tion }\end{array}$ \\
\hline $\begin{array}{c}\text { Toyoda and Eto, } \\
2019 \text { [67] }\end{array}$ & $31.5-8000$ & FDTD & $\begin{array}{l}\text { Surface } \\
\text { Impedance }\end{array}$ & $\begin{array}{c}\text { SPL, } \\
\text { Insertion Loss }\end{array}$ \\
\hline $\begin{array}{l}\text { Mondet et al., } \\
2020 \text { [56] }\end{array}$ & $100-4500$ & FDTD & $\begin{array}{c}\text { Surface } \\
\text { Impedance * }\end{array}$ & Conversion method \\
\hline Present work & $125-4000$ & FDTD & $\begin{array}{c}\text { Surface } \\
\text { Impedance }\end{array}$ & $\mathrm{T}_{30}, \mathrm{C}_{50}$ \\
\hline
\end{tabular}

*Values derived from real-valued absorption coefficients.

\section{Conclusions and Outlook}

Sound absorbers based on MPPs could be an attractive alternative to the conventional porous and fibrous absorbers when following requirements such as durability, recyclability, cleanliness and environmental sustainability. Since MPP absorbers are theoretically expected to return the same acoustic behavior regardless of their constitutive material, in principle they can be made of any green material, provided that it is hard enough to support micro-perforation. In particular, stainless steel guarantees a long service life, being an unalterable material when applied indoors, and a good hygiene, being resistant to mold and fungi. A possible continuation of this research could be a detailed LCA analysis of a selection of materials usable to make MPP. The present work aims to outline a method for the design and the numerical validation of specific sound absorbers where both active and reactive acoustical properties have to be considered. Thanks to a full-spectrum FDTD simulation method the effects of this material on the intelligibility criteria were explored. First, three custom MPP specimens were designed and manufactured using a 3D additive metal printing process. The analytical predictive models of MPP in single- and double-layer configurations were validated through experimental measurements with the impedance tube obtaining the acoustical properties in terms of sound absorption coefficients and normalized surface impedances. Then, wider surfaces of double-layer MPPs were simulated in a calibrated 3D room corresponding to a real lecture hall. Results showed that MPPs mainly operate in the central octave band of 500 and $1000 \mathrm{~Hz}$ with a further useful contribution at 250 and $2000 \mathrm{~Hz}$. Since this frequency range is the one most affecting speech intelligibility and at the same time the most undermined in historical lecture halls, MPPs seem to be a high-performance solution in cases similar to the present one. The university lecture hall taken as a case study is intended to show the positive effect of MPPs as acoustic treatment to the enhancement of speech intelligibility. In terms of time-dependence, the finite-difference 
time-domain model allowed us to better analyze both the reactive effects of the treatment and the scattering effects of the lecture hall's geometry. Finally, for all these reasons the results of the present work should be indicate a robust method to experimentally measure and test the performance of specific materials, especially considering that the demand for high-performance and sustainable materials, such as the micro-perforated panels, is expected to increasingly grow in the sector of sound absorbing treatments.

Author Contributions: Conceptualization: M.G., D.D.; data curation: M.C.; formal analysis: D.D., M.G.; funding acquisition, M.G.; investigation, M.C. and L.B.; methodology, M.G., D.D.; project administration, M.G.; resources, L.B. and M.G.; MATLAB software: M.C. and M.G.; FDTD simulation, B.H. and G.F.; supervision,M.G, and D.D.; validation, M.C., D.D.; visualization, M.C. and G.F.; writing—original draft preparation, M.C. and D.D.; writing—review and editing, D.D., G.F., B.H. and M.G. All authors have read and agreed to the published version of the manuscript.

Funding: This research was funded by the Ministero dell'Istruzione dell'Università della Ricerca (Italy), in the framework of the project PRIN 2017, grant number 2017T8SBH9: “Theoretical modeling and experimental characterization of sustainable porous materials and acoustic metamaterials for noise control".

Acknowledgments: The authors would like to thank Costantino Marmo, Donatella Alvisi and Nadia Perri, who kindly allowed us to carry out the acoustic measurements in the lecture hall taken as a case study.

Conflicts of Interest: The authors declare no conflict of interest.

Sample Availability: Samples of 3D MPPs are available from the authors.

\section{References}

1. Pan, L.; Martellotta F. A Parametric Study of the Acoustic Performance of Resonant Absorbers Made of Micro-perforated Membranes and Perforated Panels. Appl. Sci. 2020, 10, 1581. [CrossRef]

2. Asdrubali, F.; Pispola G. Properties of transparent sound-absorbing panels for use in noise barriers. J. Acoust. Soc. Am. 2007, 121, 214-221. [CrossRef]

3. Sakagami, K.; Okuzono, T. Space sound absorbers with next-generation materials: Additional sound absorption for post-pandemic challenges in indoor acoustic environments. UCL Open Environ. Prepr. 2020. [CrossRef]

4. Johnson, D. L.; Koplik J.; Dashen, R. Theory of dynamic permeability and tortuosity in fluid-saturated porous media. J. Fluid. Mech. 1987, 176, 379-402. [CrossRef]

5. Allard, J.F.; Champoux, Y. New empirical equations for sound propagation in rigid frame fibrous materials. J. Acoust. Soc. Am. 1992, 91, 3346-3353. [CrossRef]

6. Cucharero, J.; Hänninen, T.; Lokki, T. Angle-Dependent Absorption of Sound on Porous Materials. Acoustics 2020, 2, 753-765. [CrossRef]

7. Maa, D. Theory and design of microperforated panel sound-absorbing constructions. Sci. Sin. 1975, 18, 55-71.

8. Maa, D. Microperforated-panel wideband absorbers. Noise Control Eng. J. 1987 29, 77-84. [CrossRef]

9. Maa, D. Potential of microperforated panel absorber. J. Acoust. Soc. Am. 1998 104, 2861-2866. [CrossRef]

10. Tayong, R.; Leclaire, P. Holes Interaction Effects under high and medium Sound Intensities for Micro-perforated panels design. In Proceedings of the 10th Congress Francais d'Acoustique, Lyon, France, 12-16 April 2010.

11. Melling, T.H. The acoustic impendance of perforates at medium and high sound pressure levels. J. Sound Vib. 1973, $29,1-65$. [CrossRef]

12. Atalla, N.; Sgard, F. Modeling of perforated plates and screens using rigid frame porous models. J. Sound Vib. 2007, 303, 195-208. [CrossRef]

13. Cobo, P.; Simon, F. Multiple-Layer Microperforated Panels as Sound Absorbers in Buildings: A Review. Buildings 2019, 9, 53. [CrossRef]

14. Lee, D.H.; Kwon, Y.P. Estimation of the absorption performance of multiple-layer perforated panel systems by transfer matrix method. J. Sound Vib. 2004, 278, 847-860. [CrossRef]

15. Sakagami, K.; Morimoto, M.; Koike, W. A numerical study of double-leaf microperforated panel absorbers. Appl. Acoust. 2019, 2006, 67-609. [CrossRef]

16. Hoshi, K.; Hanyu, T.; Okuzono, T.; Sakagami, K.; Yairi, M.; Harada, S.; Takahashi, S.; Ueda, Y. Implementation experiment of a honeycomb-backed MPP sound absorber in a meeting room.Appl. Acoust. 2020, 157, 107000. [CrossRef]

17. Tsay, Y.S.; Yeh, C.Y. A Machine Learning Based Prediction Model for the Sound Absorption Coefficient of Micro-Expanded Metal Mesh (MEMM). Appl. Sci. 2020, 10, 7612. [CrossRef] 
18. Arvidsson, E.; Nilsson, E.; Hagberg, D.B.; Karlsson, O.J. The Effect on Room Acoustical Parameters Using a Combination of Absorbers and Diffusers-An Experimental Study in a Classroom. Acoustics 2020, 2, 505-523. [CrossRef]

19. Choi, Y. Evaluation of acoustical conditions for speech communication in active university classrooms. Appl. Acoust. 2020, 159, 107089. [CrossRef]

20. D'Orazio, D.; De Salvio, D.; Anderlucci, L.; Garai, M. Measuring the speech level and the student activity in lecture halls: Visual-vs blind-segmentation methods. Appl. Acoust. 2020, 169, 107-448. [CrossRef]

21. Brill, L.C.; Smith, K.; Wang, L.M. Building a sound future for students: Considering the acoustics of occupied active classrooms.Acoust. Today 2018, 14, 14-22.

22. Hodgson, M.; Rempel, R.; Kennedy, S. Measurement and prediction of typical speech and background-noise levels in university classrooms during lectures. J. Acoust. Soc. Am. 1999, 105, 226-233. [CrossRef]

23. Puglisi, G.E.; Bolognesi, F.; Shtrepi, L.; Warzybok, A.; Kollmeier, B.; Astolfi, A. Optimal classroom acoustic design with sound absorption and diffusion for the enhancement of speech intelligibility. J. Acoust. Soc. Am. 2017, 141, 3456-3457. [CrossRef]

24. Visentin, C.; Prodi, N.; Cappelletti, F.; Torresin, S.; Gasparella, A. Using listening effort assessment in the acoustical design of rooms for speech. Build Environ. 2018, 136, 38-53. [CrossRef]

25. Chung, J.Y.; Blaser, D.A. Transfer function method of measuring induct acoustic properties. I. Theory. J. Acoust. Soc. Am. 1980, 68, 907-913. [CrossRef]

26. EN ISO 10534-2:2001. Acoustics-Determination of Sound Absorption Coefficient and Impedance in Impedance Tubes-Part.2: TransferFunction Method; International Organization for Standardization: Geneva, Switzerland, 2001.

27. Fratoni, G.; D'Orazio, D.; De Salvio, D.; Garai, M. Predicting speech intelligibility in university classrooms using geometrical acoustic simulations. In Proceedings of the 16th IBPSA, Rome, Italy, 2-4 September 2019.

28. Hamilton, B.; Webb, C.J. Room acoustics modelling using GPU-accelerated finite difference and finite volume methods on a face-centered cubic grid. In Proceedings of the Digital Audio Effects (DAFx), Maynooth, Ireland, 2-6 September 2013; $336-343$.

29. Ning, J.F.; Ren, S.W.; Zhao, G.P. Acoustic properties of micro-perforated panel absorber having arbitrary cross-sectional perforations. Appl. Acoust. 2016, 111, 135-142. [CrossRef]

30. MATLAB, Version 9.6.0.1072779 (R2019a); The MathWorks Inc.: Natick, MA, USA, 2019.

31. ITA-Toolbox, Open source MATLAB toolbox for acoustics developed by the Institute of Technical Acoustics of the RWTH Aachen University, Neustrasse 50, 52056, Aachen, Germany. In Proceedings of the DAGA 2017, Kiel, Germany, 6-9 March 2017.

32. Corredor-Bedoya, A.C.; Acuña, B.; Serpa, A.L.; Masiero, B. Effect of the excitation signal type on the absorption coefficient measurement using the impedance tube. Appl. Acoust. 2020, 171, 107659. [CrossRef]

33. Sakagami, K.; Kusaka, M.; Okuzono, T.; Nakanishi, S. The Effect of deviation due to the manufacturing accuracy in the parameters of an MPP on its acoustic properties: Trial production of MPPs of different hole shapes using 3D printing. Acoustics 2020, 2, 605-606. [CrossRef]

34. Randeberg, R.T. Perforated Panel Absorbers with Viscous Energy Dissipation Enhanced by Orifice Design; Ph.D. Dissertation, Department of Telecommunication, Norwegian University of Science and Technology, Trondheim, Norway, June 2000.

35. Sakagami, K.; Morimoto, M.; Yairi, M. A note on the effect of vibration of a microperforated panel on its sound absorption characteristics. Acoust. Sci. Technol. 2005, 26, 204-207. [CrossRef]

36. Courant, R.; Friedrichs, K.; Lewy, H. Über die partiellen Differenzengleichungen der mathematischen Physik. Math. Annal. 1928, 100, 32-74. [CrossRef]

37. Botteldooren, D. Finite-difference time-domain simulation of low-frequency room acoustic problems. J. Acoust. Soc. Am. 1995, 98, 3302-3308. [CrossRef]

38. Bilbao, S.D. Numerical Sound Synthesis; John Wiley \& Sons: Hoboken, NJ, USA, 2009.

39. Savioja, L. Real-time 3D finite-difference time-domain simulation of low-and mid-frequency room acoustics. In Proceedings of the 13th International Conference on Digital Audio Effects, Maynooth, Ireland, 6-10 September 2010.

40. Kowalczyk, K.; Van Walstijn, M. Room acoustics simulation using 3-D compact explicit FDTD schemes. IEEE Trans. Audio Speech Lang. Process. 2011, 19, 34-46. [CrossRef]

41. Hamilton, B. Finite Difference and Finite Volume Methods for Wave-Based Modelling of Room Acoustics. Ph.D. Dissertation, University of Edinburgh, Edinburgh, UK, 2016.

42. Micikevicius, P. 3D finite difference computation on GPUs using CUDA. In Proceedings of the 2nd Workshop on General Purpose Processing on Graphics Processing Units, Washington, DC USA, 8 March 2009; pp. 79-84.

43. Arenas, J.P.; Sakagami, K. Sustainable Acoustic Materials; MDPI: Basel, Switzerland, 2020; p. 6540.

44. Bistafa, S.R.; Bradley, J.S. Predicting speech metrics in a simulated classroom with varied sound absorption. J. Acoust. Soc. Am. 2001, 109, 1474-1482. [CrossRef] [PubMed]

45. Reich, R.; Bradley, J. Optimizing classroom acoustics using computer model studies. Can. Acoust. 1998, $26,15-21$.

46. Bistafa, S.R.; Bradley, J.S. Predicting reverberation times in a simulated classroom. J. Acoust. Soc. Am. 2000, 108, 1721-1731. [CrossRef]

47. IEC 60268-16. Sound System Equipment-Part 16: Objective Rating of Speech Intelligibility by Speech Transmission Index; IEC: Geneva, Switzerland, 2020.

48. Garai, M.; Pompoli, F. A simple empirical model of polyester fibre materials for acoustical applications. Appl. Acoust. 2005, 66, 1383-1398. [CrossRef] 
49. Martellotta, F. Optimizing stepwise rotation of dodecahedron sound source to improve the accuracy of room acoustic measures. J. Acoust. Soc. Am. 2013, 134, 2037-2048. [CrossRef]

50. ISO 3382-2. Acoustics-Measurement of Room Acoustic Parameters-Part 2: Reverberation Time in Ordinary Rooms; International Organization for Standardization: Geneva, Switzerland, 2008.

51. SketchUp, Trimble Inc., Version Make; 935 Stewart Drive, Sunnyvale CA (USA) 94085, 2017.

52. Vorländer, M. Auralization; Springer: Aachen, Germany, 2008.

53. Postma, B.N.; Katz, B.F. Perceptive and objective evaluation of calibrated room acoustic simulation auralizations. J. Acoust. Soc. Am. 2016, 140, 4326-4337. [CrossRef]

54. Choi, Y. J. Effects of periodic type diffusers on classroom acoustics. Appl. Acoust. 2013, 74, 694-707. [CrossRef]

55. Okuzono, T.; Shadi, M.; Sakagami, K. Potential of Room Acoustic Solver with Plane-Wave Enriched Finite Element Method. Appl. Sci. 2020, 10, 1969. [CrossRef]

56. Mondet, B.; Brunskog, J.; Jeong, C.H.; Rindel, J.H. From absorption to impedance: Enhancing boundary conditions in room acoustic simulations. Appl. Acoust. 2020, 157, 106884. [CrossRef]

57. Vercammen, M. On the Revision of ISO 354, Measurement of the Sound Absorption in the Reverberation Room; ISO/WD: Geneva, Switzerland, 2018.

58. Jeong, C.H. Converting Sabine absorption coefficients to random incidence absorption coefficients. J. Acoust. Soc. Am. 2013, 133, 3951-3962. [CrossRef]

59. Takumi, Y.; Okuzono, T.; Sakagami, K. Locally implicit time-domain finite element method for sound field analysis including permeable membrane sound absorbers. Acoust. Sci. Technol. 2020, 41, 689-692.

60. Cheng, Y.; Cheng, L.; Pan, J. Absorption of oblique incidence sound by a finite micro-perforated panel absorber. J. Acoust. Soc. Am. 2013, 133, 201-209.

61. Bilbao, S.; Hamilton, B.; Botts, J.; Savioja, L. Finite volume time domain room acoustics simulation under general impedance boundary conditions. In IEEE-ACM Transactions on Audio, Speech, and Language Processing; IEEE: Piscataway, NJ, USA, 2016; Volume 24, pp. 161-173.

62. Hamilton, B.; Webb, C.J.; Fletcher, N.D.; Bilbao, S. Finite difference room acoustics simulation with general impedance boundaries and viscothermal losses in air: Parallel implementation on multiple GPUs. In Proceedings of the Int. Symp. Musical Room Acoust. La Plata, Argentina, 11-13 September 2016.

63. D'Orazio, D.; Fratoni, G.; Rovigatti, A.; Hamilton, B. Numerical simulations of Italian opera houses using geometrical and wavebased acoustics methods. In Proceedings of the 23rd International Congress on Acoustics, Aachen, Germany, 9-13 September 2019.

64. Vorländer, M. Computer simulations in room acoustics: Concepts and uncertainties. J. Acoust. Soc. Am. 2013, 133, 1203-1213. [CrossRef] [PubMed]

65. Okuzono, T.; Sakagami, K. A frequency domain finite element solver for acoustic simulations of 3D rooms with microperforated panel absorbers. Appl. Acoust. 2018, 129, 1-12. [CrossRef]

66. Okuzono, T.; Sakagami, K.A finite-element formulation for room acoustics simulation with microperforated panel sound absorbing structures: Verification with electro-acoustical equivalent circuit theory and wave theory. Appl. Acoust. 2015, 95, 20-26. [CrossRef]

67. Toyoda, M.; Eto, D. Prediction of microperforated panel absorbers using the finite-difference time-domain method. Wave Motion 2019, 86, 110-124. [CrossRef]

68. Liu, J.; Herrin, D.W. Enhancing micro-perforated panel attenuation by partitioning the adjoining cavity. Appl. Acoust. 2010, 71, 120-127. [CrossRef]

69. Naderyan, V.; Raspet, R.; Hickey, C.J.; Mohammadi, M. Acoustic end corrections for micro-perforated plates. J. Acoust. Soc. Am. 2019, 146, EL399-EL404. [CrossRef] 